was $0.04 \pm 0.3 \%$ and $\mathrm{COV}$ was $1.8 \pm 1.2 \%$ and the inter-observer average difference was $0.55 \pm 1.4 \%$ and COV was $4.2 \pm 4.6 \%$.

Conclusion A volume derived SDI from cine CMR strongly predicts remodelling post CRT. It is a highly reproducible measurement that has significant potential clinical implications in the future.

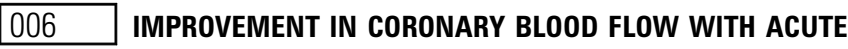 BIVENTRICULAR PACING IS PREDOMINANTLY DUE TO AN INCREASE IN A DIASTOLIC BACKWARD-TRAVELLING DECOMPRESSION (SUCTION) WAVE}

doi:10.1136/heartjnl-2012-301877b.6

A Kyriacou, * Z I Whinnett, S Sen, P Pabari, D W Davies, N S Peters, P Kanagaratnam, J Mayet, A D Hughes, D P Francis, J E Davies. NHLI, St Mary's Hospital, Imperial College Healthcare NHS Trust, London, UK

Background Normal coronary blood flow is principally determined by a backward-travelling decompression (suction) wave in diastole. This wave may be attenuated in chronic heart failure, reducing blood flow, as regional relaxation and contraction overlap in timing. We hypothesised that biventricular pacing by restoring left ventricular (LV) synchronisation and improving LV relaxation might increase this decompression wave, improving coronary flow.

Method and Results Ten CHF patients ( 9 males; age $65 \pm 12$; EF $26 \pm 7 \%$ ) with left bundle branch block (LBBB, ORS duration $174 \pm 18 \mathrm{~ms}$ ) were atrio-biventricularly paced at $100 \mathrm{bpm}$. LV pressure was measured and wave intensity calculated from invasive coronary flow velocity and pressure, with native conduction (LBBB)

Abstract 006 Table 1 Cumulative wave intensity of major left coronary artery waves and comparison of these between all four pacing states. Data are presented as mean \pm SEM

\begin{tabular}{|c|c|c|c|c|c|c|}
\hline $\begin{array}{l}\text { Wave Intensity } \\
\text { (AUC) } \times 10^{3} \\
\mathrm{~W} / \mathrm{m}^{2} / \mathrm{s}\end{array}$ & LBBB & Biv-40 & BiV-120 & BiV-OPt & $\begin{array}{l}\text { p Value } \\
\text { (BiV-0pt } \\
\text { vs LBBB) }\end{array}$ & $\begin{array}{l}\text { p Value } \\
\text { (Biv-40 } \\
\text { vs LBBB }\end{array}$ \\
\hline \multicolumn{7}{|l|}{ Systole } \\
\hline $\begin{array}{l}\text { 1. Forward } \\
\text { compression }\end{array}$ & $9.1 \pm 1.9$ & $8.6 \pm 1.9$ & $11.4 \pm 2.3$ & $12.1 \pm 2.5$ & 0.04 & 0.51 \\
\hline $\begin{array}{l}\text { 2. Backward } \\
\text { compression }\end{array}$ & $7.5 \pm 1.5$ & $7.2 \pm 1.7$ & $9.0 \pm 1.6$ & $9.9 \pm 1.9$ & 0.01 & 0.75 \\
\hline $\begin{array}{l}\text { Net wave } \\
\text { contribution to } \\
\text { forward flow } \\
\text { (1 minus } 2 \text { ) }\end{array}$ & $1.6 \pm 1.4$ & $1.4 \pm 1.0$ & $2.4 \pm 1.3$ & $2.3 \pm 1.7$ & & \\
\hline \multicolumn{7}{|l|}{ Diastole } \\
\hline $\begin{array}{l}\text { 3. Forward } \\
\text { decompression }\end{array}$ & $2.1 \pm 0.5$ & $3.2 \pm 0.7$ & $3.5 \pm 0.8$ & $3.3 \pm 0.6$ & 0.15 & 0.20 \\
\hline $\begin{array}{l}\text { 4. Late forward } \\
\text { compression } \\
\text { (suction) }\end{array}$ & $3.2 \pm 0.8$ & $2.4 \pm 0.9$ & $2.7 \pm 0.6$ & $2.8 \pm 0.9$ & 0.76 & 0.42 \\
\hline $\begin{array}{l}\text { 5. Backward } \\
\text { decompression } \\
\text { (suction) }\end{array}$ & $7.8 \pm 1.4$ & $7.6 \pm 1.3$ & $10.1 \pm 2.0$ & $10.4 \pm 2.1$ & 0.01 & 0.71 \\
\hline \multirow[t]{2}{*}{$\begin{array}{l}\text { Net wave } \\
\text { contribution } \\
\text { to forward } \\
\text { flow ( } 5 \text { plus } \\
4 \text { minus } 3 \text { ) }\end{array}$} & $8.8 \pm 1.9$ & $6.7 \pm 1.8$ & $9.3 \pm 2.4$ & $9.9 \pm 2.1$ & & \\
\hline & & & & & $\mathrm{p}$ Value & \\
\hline $\begin{array}{l}\text { Proportion of } \\
\text { diastolic } \\
\text { contribution } \\
\text { to total } \\
\text { net wave } \\
\text { contribution } \\
\text { to forward flow }\end{array}$ & $85 \pm 5 \%$ & $83 \pm 4 \%$ & $80 \pm 6 \%$ & $81 \pm 5 \%$ & 0.62 & \\
\hline
\end{tabular}
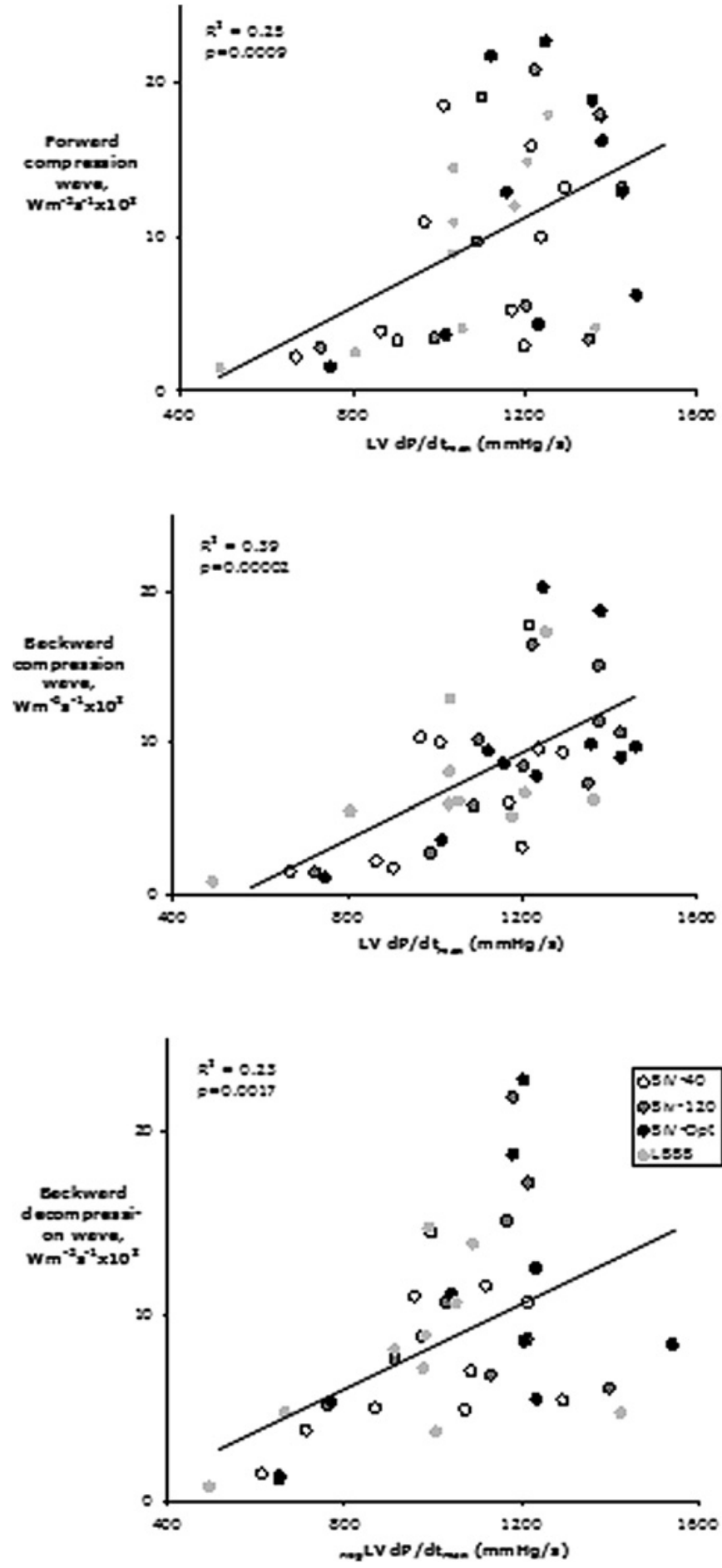

Abstract 006 Figure 1 Impact of $L V d p / d t_{\max }$ and $L V{ }_{\text {neg }} d p / \mathrm{dt}_{\max }$ on their temporally corresponding coronary waves. In each part of the cardiac cycle, the peak rate of intraventricular pressure change (LV dp/ $\mathrm{dt}_{\max }$ for systole, and LV negdP/dt $\mathrm{dt}_{\max }$ for diastole) correlated with the corresponding waves, consistent with myocardial compression and decompression of the coronary microcirculation generating the waves.

and during biventricular pacing at atrioventricular (AV) delays of $40 \mathrm{~ms}$ (BiV-40), $120 \mathrm{~ms}$ (BiV-120), and separately pre-identified haemodynamically-optimal AV delay (BiV-Opt). Compared against LBBB, BiV-Opt enhanced coronary flow by $15 \pm 4 \%(p=0.003), L V$ $\mathrm{dP} / \mathrm{dt}_{\max }$ by $19 \pm 4 \% \quad(\mathrm{p}<0.001)$ and $n e g d P / \mathrm{dt}_{\max }$ by $16 \pm 3 \%$ $(p<0.001)$. The cumulative intensity of the diastolic backward decompression (suction) wave increased by $36 \pm 8 \%(p=0.011)$. The 
majority of the increase in coronary flow occurred in diastole $(64 \pm 8 \%, \mathrm{p}=0.03)$. The systolic compression waves also increased, forward by $33 \pm 11 \% \quad(p=0.043)$ and backward by $33 \pm 10 \%$ $(p=0.014)$. BiV-120 generated a smaller LV dP/dt $\max$ (by $23 \pm 12 \%$, $\mathrm{p}=0.034$ ) and $n e g d P / d t_{\max }$ (by $23 \pm 10 \%, p=0.039$ ) increase than $\mathrm{BiV}-\mathrm{OPT}$, against $\mathrm{LBBB}$ as reference; BiV-Opt and BiV-120 were not statistically different in coronary flow or waves. BiV-40 was no different from LBBB.

Conclusions When biventricular pacing improves left ventricular contractility, it increases coronary blood flow, predominantly by increasing the dominant diastolic backward decompression (suction) wave.

\section{SHOULD CURRENT MODALITIES OF VV OPTIMISATION BE TRUSTED? AN ASSESSMENT OF THE INTERNAL VALIDITY OF ECHOCARDIOGRAPHIC, ELECTROCARDIOGRAPHIC AND HAEMODYNAMIC MODALITIES OF OPTIMISATION}

doi:10.1136/heartjnl-2012-301877b.7

Andreas Kyriacou, ${ }^{*}$ M Li Kam Wa, P Pabari, P Kanagaratnam, N S Peters, J Mayet, D P Francis, Z I Whinnett. St Marys Hospital, Imperial College Healthcare NHS Trust, London, UK

Background In atrial fibrillation (AF), VV optimisation of biventricular pacemakers can be examined in isolation. We used this approach to evaluate the internal validity of three VV optimisation methods.

A
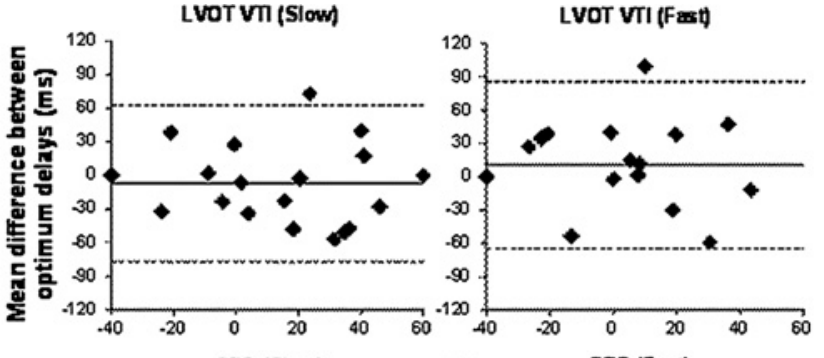

B
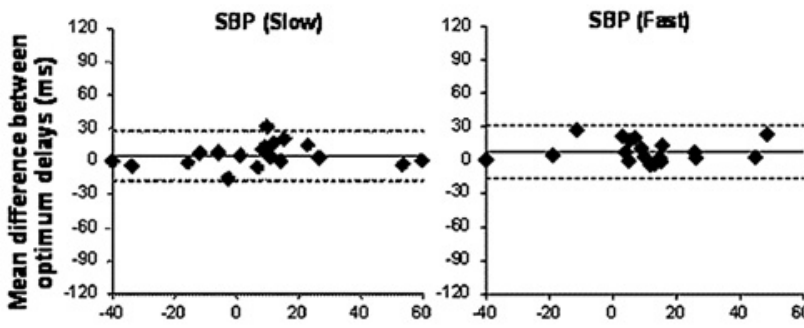

c

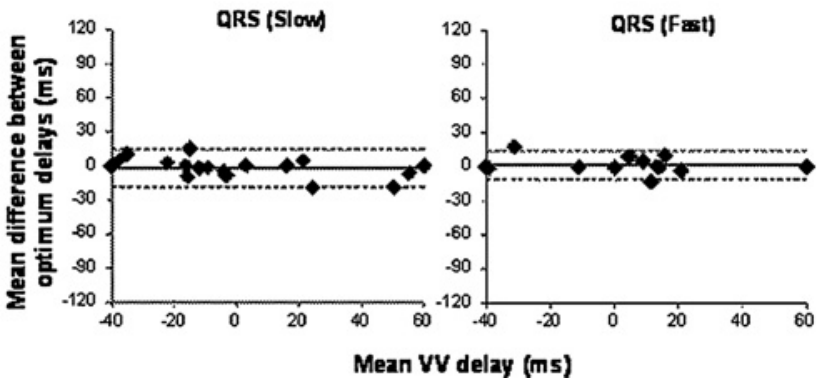

Abstract 007 Figure 1 The reproducibility (SD of the difference, SDD in $\mathrm{ms}$ ) of LVOT VTI (A) is equally poor at the slow (31 ms) and fast ( $35 \mathrm{~ms})$ heart rates. SBP reproducibility (B) was better than LVOT VTI at slow $(10 \mathrm{~ms}, \mathrm{p}<0.01)$ and fast heart rates $(9 \mathrm{~ms}, \mathrm{p}<0.01)$. The reproducibility of the QRS width $(C)$ was also better at slow $(8 \mathrm{~ms}, \mathrm{p}<0.01)$ and fast $(6 \mathrm{~ms}, \mathrm{p}<0.01)$ rates.
Methods 20 patients (16 men, age 75 7 ) in AF were optimised, at two paced heart rates, by LVOT VTI (flow), non-invasive arterial pressure, and ECG (minimising ORS duration). Each optimisation method was evaluated by: singularity (unique peak of function), reproducibility of optimum, and biological plausibility of the distribution of optima.

Results The reproducibility (SD of the difference, SDD) of the optimal VV delay is $10 \mathrm{~ms}$ for pressure, vs $8 \mathrm{~ms}(\mathrm{p}=\mathrm{NS})$ for ORS and $34 \mathrm{~ms}(p<0.01)$ for flow. Singularity of optimum is $85 \%$ for pressure, $63 \%$ for ECG and $45 \%$ for flow $\left(\chi^{2}=10.9, p<0.005\right)$. The distribution of pressure optima is biologically plausible, with $80 \%$ LV pre-excited $(p=0.007)$. The distributions of ECG (55\% LV preexcitation) and flow (45\% LV pre-excitation) optima are no better than random $(\mathrm{p}=\mathrm{NS})$. The pressure-derived optimal VV delay is unaffected by the paced rate: SDD between slow and fast heart rate is $9 \mathrm{~ms}$, no different from the reproducibility SDD at both heart rates, $(p=N S)$.

Conclusions Using non-invasive arterial pressure, VV delay optimisation is achievable with good precision, satisfying all 3 criteria of internal validity, and the optimum is unaffected by heart rate. Neither ORS minimisation nor LVOT VTI satisfy all validity criteria and are therefore weaker candidate modalities for VV optimisation.

\section{LEFT VENTRICULAR HYPERTROPHY IS ASSOCIATED WITH INTRAMURAL DYSSYNCHRONY ON EXERCISE IN PATIENTS WITH HEART FAILURE AND NORMAL EJECTION FRACTION}

doi:10.1136/heartjnl-2012-301877b.8

${ }^{1} \mathrm{Y}$ T Tan, ${ }^{*} \mathrm{~F}$ Wenzelburger, ${ }^{1} \mathrm{~F}$ Leyva, ${ }^{2} \mathrm{~J}$ Sanderson. ${ }^{1}$ University of Birmingham, Birmingham, UK; ${ }^{2}$ The Chinese University of Hong Kong, Hong Kong, China

Background The pathophysiology of heart failure with normal ejection fraction (HFNEF) is complex and not fully understood. We hypothesised that left ventricular hypertrophy (LVH) which is found in most patients with HFNEF might lead to intramural dyssynchrony and uncoupling of the complex 3-dimensional motion of the left ventricle (LV) particularly on exercise.

Method 33 patients with the clinical diagnosis of HFNEF (age $69 \pm 11$ years, 19 female, EF $60 \pm 7 \%$ ) and LVH (according to American Society of Cardiology, female $>95 \mathrm{~g} / \mathrm{m}^{2}$, male $115 \mathrm{~g} / \mathrm{m}^{2}$ ) underwent detailed 2D-echocardiography at rest and on supine exercise. They were compared to 41 clinically diagnosed HFNEF patients without LVH (age 73 \pm 8 years, 26 females, EF $61 \pm 7 \%$ ) and 35 age-matched control subjects (age $71 \pm 7$ years, 27 females, EF $63 \pm 7)$. All subjects underwent cardiopulmonary exercise test to assess peak oxygen consumption (peak VO2). Echocardiographic images were analysed off-line. Apical and basal rotation and radial displacement were measured by speckle tracking. Longitudinal displacement was assessed by colour tissue Doppler imaging. Raw data and timing of events were analysed using a custom-written interpolation algorithm. SDSM (SD of four LV peak systolic motions: basal and apical rotation, longitudinal and radial displacement) was calculated.

Results SDSM was comparable at rest for all three groups but controls showed the highest reduction in SDSM compared to both groups of patients on exercise. Patients with LVH had the smallest reduction in SDSM implying greater dyssynchrony in LV motions on exercise. SDSM on exercise correlated with left ventricular mass index $(\mathrm{r}=0.362, \mathrm{p}=0.002)$ and $\mathrm{VO}_{2} \max (\mathrm{r}=-0.319$, $\mathrm{p}=0.011$ )

Conclusion LVH in patients with HFNEF is associated with intramural dyssynchrony and uncoupling of the complex 3-dimensional LV motions on exercise. This might contribute to their exertional symptoms. 